\title{
Entrevista al Dr. Baruch Martínez Zepeda
}

\author{
baruch.martinez@hotmail.com
}

Baruch Martínez Zepeda es Investigador Asociado "C" de Tiempo Completo del Centro de Estudios Clásicos del Instituto de Investigaciones Filológicas de la Universidad Nacional Autónoma de México. Obtuvo la licenciatura en Letras Clásicas en la misma casa de estudios (2009); la maestría en Filologia, letterature e storia dell'antichità en la Università degli Studi Roma Tre (2013) y el Dottorato di Ricerca in Antichità classiche e loro fortuna. Archeologia, filologia, storia en la Università degli Studi di Roma "Tor Vergata" (2018). Sus principales campos de investigación son la poesía flavia (Estacio) y la crítica textual. Entre sus publicaciones más destacadas, se encuentran las traducciones de: Giovanni Pico della Mirandola, Discurso sobre la dignidad del hombre (México: unam, 2016) y Ricardo de Bury, Philobiblon (México, unam, 2018), así como el artículo "A Note on Ovid, Her. 6.117-18", en The Classical Quarterly (2019).

Entrevistadora: Ana Laura Zavala Díaz. Doctora en Letras por la Facultad de Filosofía y Letras de la Universidad Nacional Autónoma de México. Investigadora del Seminario de Edición Crítica de Textos del Instituto de Investigaciones Filológicas.

\section{A.L.Z.D. ¿Qué autores edita críticamente?}

B.M.Z. Trabajo con Estacio, un poeta épico romano que vivió durante el siglo i d. C., y de quien conservamos la Tebaida, la Aquileida (que el autor dejó inconclusa) y las Silvas (perdimos el Carmen de bello Germanico y quizá una Agaue). En lo específico me dedico a la Tebaida, cuya tradición textual es muy compleja, pues en el último catálogo de manuscritos estacianos se enumeran 254 del poema, y, al contrario de lo que se había creído hasta hace pocas décadas, no es posible demostrar filiaciones claras entre ellos.

En este momento, estoy realizando una edición crítica digital de los libros 5 y 6 de la Tebaida de Estacio, para un proyecto titulado Thebarum fabula, dirigido por Cecilia Criado Boado de la Universidad de Santiago de Compostela. El proyecto consiste en una biblioteca online donde se recopilan las fuentes del mito tebano en lengua original (con aparato crítico), acompañadas de una traducción, sobre todo al inglés. Mi trabajo es, pues, fijar un texto y elaborar un aparato crítico predominantemente negativo (es positivo sólo cuando el consensus codicum transmite la lección errónea), a partir de los aparatos de las dos últimas ediciones de la Tebaida: la de 
D. E. Hill (Leiden, 1983) y la de J. B. Hall, A. L. Ritchie y M. J. Edwards (Cambridge, 2007-2008). Mi intervención sólo se lleva a cabo en los lugares que se crean más oportunos (el aparato es tan exhaustivo como lo juzgue pertinente, pero mi criterio principal consiste en referir únicamente las lecciones que han sido impresas por los diversos editores a partir del siglo XIX). Aunado a ello, se adapta una traducción al inglés - libre y disponible en Internet - para que refleje de la manera más fiel posible el texto latino que se ofrece.

Para fijar una u otra variante o enmendar el texto, recurro a los mismos principios que cualquier editor de textos (lectio difficilior, usus scribendi, loci paralleli, etc.). Cabe señalar que en el caso de Estacio esta operación se vuelve aún más necesaria, porque, como dije hace un momento, no es posible establecer con claridad parentescos entre los diversos códices, es decir, no hay un stemma codicum, por lo que no se puede descartar una lectura a priori sólo por tratarse de un determinado manuscrito; por ello, salvo aquellas que sean evidentemente erróneas, todas deben evaluarse. Como ejemplo de esto, podemos citar Tebaida 5.29-32, pasaje en el que la heroína Hipsípila responde a Adrasto, ante la petición de éste de hablar sobre la masacre de Lemnos: "inmania uulnera, rector, | integrare iubes, Furias et Lemnon et atris | arma inserta toris debellatosque pudendo | ense mares" ["oh general, me pides revivir grandes heridas, las Furias, y Lemnos, y las armas traspasadas en los funestos lechos, y los hombres sometidos por armas vergonzosas"]. En el v. 30, existen las variantes artis y atris. La mayoría y más antiguos manuscritos leen artis, que no da un buen sentido: "los lechos estrechos". Sólo algunos pocos códices recentiores tienen la lectura atris, que, sin duda, resulta mucho más satisfactoria pese a la (aparente) escasa autoridad de los testimonia de donde proviene: "los funestos lechos" (recuerdo aquí la prudente advertencia de G. Pasquali: "recentiores, non deteriores").

\section{A.L.Z.D. ¿En qué tipo de soporte trabaja?}

B.M.Z. Para la edición que ahora realizo, empleo el TEI (Text Encoding Initiative), una codificación digital de textos de humanidades, la cual, además de contar con las grandes ventajas de todas las herramientas informáticas (por ejemplo, corregir errores de manera inmediata), ofrece otras, como la presentación del texto de forma clara y sencilla. El TEI sólo tiene aparentes desventajas, pues cualquier problema que surja se puede resolver a través de la propia experiencia o consultando a los especialistas. El resultado es una interfaz muy amigable. Hay dos ventanas: en la de la izquierda, se encuentra el texto en latín; las palabras que tienen diversas lecturas se mues- 


\section{Entrevista al Dr. Baruch Martínez Zepeda}

tran con otro color, y si se pasa encima el cursor del ratón se abre una "pop up box" donde se despliegan los testimonia que refieran dicha lección. Y en la ventana derecha se presenta la traducción que está anclada al texto latino, es decir que ambos textos se mueven simultáneamente.

\section{A.L.Z.D. ¿A qué tipo de lector dirige su propuesta de edición?}

B.M.Z. Siendo Internet el medio empleado para la divulgación del trabajo, sabemos que llegará a todo tipo de público; sin embargo, está dirigido, sobre todo, a especialistas. En este tipo de edición, a diferencia de una tradicional, el estudioso tiene a su alcance una forma fácil y rápida de acceder a materiales con altos estándares científicos y con todas las ventajas de la tecnología informática (por ejemplo, realizar búsquedas muy específicas en pocos instantes).

A.L.Z.D. ¿Qué tan dificil es hacer edición de textos clásicos y crítica textual desde México?

B.M.Z. Sin duda, antes resultaba imposible, pero ahora lo es un poco menos. Como bien sabemos, casi todo el patrimonio manuscrito está en las bibliotecas europeas (por ejemplo, la Biblioteca Ambrosiana en Milán, la Biblioteca Apostolica Vaticana en Roma, la Biblioteca Medicea Laurenziana en Florencia, la Bibliothèque Nationale de France en París, la British Library en Londres, la Osterreichische Nationalbibliothek en Viena). En los últimos años, muchas de ellas han digitalizado parte de su acervo, en algunos casos en una modesta porción (como en la British Library), pero en otros el esfuerzo ha sido mucho más notorio (por ejemplo, en la Biblioteca Medicea Laurenziana, la Bibliothèque Nationale de France y la Biblioteca Apostolica Vaticana). Dichos materiales se ofrecen online de forma abierta y gratuita, así que son accesibles prácticamente desde cualquier lugar del mundo, basta con contar con una computadora y una conexión a Internet. Lo mismo se puede decir de muchas de las ediciones de textos clásicos - sobre todo, las publicadas entre la invención de la imprenta y el siglo XIX-, que también están disponibles en las distintas bibliotecas en línea (como Google Books o Internet Archive). Así, un estudioso puede recorrer siglos y siglos de la historia de un texto en tan sólo pocos minutos, iy todo desde una computadora!

Justo ahora, estoy escribiendo un artículo sobre problemas textuales y tradición exegética en los versos 1-295 del libro 5 de la Tebaida de Estacio. Los materiales a mi disposición son 30 manuscritos (varios de ellos con glosas), 3 incunables y alrededor de 50 obras más, entre ediciones, traducciones y comentarios, muchos de los cuales los obtuve en Internet. De 


\section{Entrevista al Dr. Baruch Martínez Zepeda}

modo que, para recopilar todo esto hace 20 años, hubiera tenido que darle la vuelta a Europa.

Sin embargo, es importante reconocer que las cosas no resultan siempre tan fáciles. Si bien algunas reproducciones informáticas de manuscritos son de muy alta calidad, otras no, y puede también darse el caso de que, per se, la tinta del códice se encuentre borrosa. En ambos casos, será necesario revisar el códice en persona y, en el segundo, incluso se requiere usar una lámpara de rayos UV si se pretende trabajar seriamente con él. Pero vale la pena examinar dichos materiales, pues ello permite realizar trabajos rigurosos sobre crítica textual, y entablar así, poco a poco, un diálogo con las academias más importantes del mundo. 